\title{
An Investigation of Multiple Asymmetric Threshold Contagions Effects of U.S. Stock Market to Major Industrialized Countries under Turbulent Economic Conditions
}

\author{
Yeong-Jia Goo, Ming-Chang Yang \\ Department of Business Administration, National Taipei University \\ Email: goo@mail.ntpu.edu.tw, s810631111@gm.ntpu.edu.tw
}

How to cite this paper: Goo, Y.-J., \& Yang, M.-C. (2021). An Investigation of Multiple Asymmetric Threshold Contagions Effects of U.S. Stock Market to Major Industrialized Countries under Turbulent Economic Conditions. Modern Economy, 12, 804-825. https://doi.org/10.4236/me.2021.124040

Received: March 9, 2021

Accepted: April 20, 2021

Published: April 23, 2021

Copyright ( 2021 by author(s) and Scientific Research Publishing Inc. This work is licensed under the Creative Commons Attribution International License (CC BY 4.0).

http://creativecommons.org/licenses/by/4.0/

\section{(c) (i) Open Access}

\begin{abstract}
Researchers and academic institutions frequently use the conventional Threshold AR model. However, the model uses zero or a single random value as a threshold to convey limited information. This study intends to explore multiple asymmetric threshold effects of U.S. stock market to five major industrialized countries during turbulent economic conditions. Daily stock index returns, ranging from 1998 to 2019, are collected. A three random thresholds TAR model is built; Four hypotheses are proposed; Grid search algorithm is programmed; The testing procedure includes: linear and non-linear unit roots, structural break, likelihood ratio, Wald, and residual diagnoses are tested. The findings are as follows: The four hypotheses are significant in most of five major countries except for U.K. and Germany of contagions effects. The newly proposed multiple TAR model is superior to the traditional TAR model. During the financial crisis period, the contagions effects are greater, the threshold effects are significant, and the combined threshold contagions effects are stronger.
\end{abstract}

\section{Keywords}

Threshold Regression Models, Financial Crisis, Contagions Effects

\section{Introduction}

Towards the end of 1990s, Forbes and Rigobon (2002) have defined a phenomenon called "contagion". At present, it is widely used to describe the impact of financial disruption from one country to another. Contagion has been defined as "a significant increase in cross-market linkages after a shock to one country (or 
group of countries)"; otherwise, a continued market correlation at high levels is considered to be "no contagion, only interdependence".

In the past, the financial empirical analysis is commonly used in time series models to analyze stock returns. The analysis for stock returns focuses on empirical research on the correlation between stock returns. It is used to detect predictable pattern of existing stock returns. Predictable patterns imply profitable trading rules, while rejecting the efficient market hypothesis. That is, the empirical evidence of Fama and French (1989) and Potterba and Summers (1988) and the stock returns have long-term memory or mean regression as indicated by Ding et al. (1993). The conclusion made from the studies is that the stock returns do not follow the random walk process all the time. Cross country researches, of which include Kim and Rogers (1995), Koutmos and Booth (1995), show that national stock returns are notably related with each other and that the interdependence between international stock markets increases with time.

In the several crises that have occurred in the past three decades, there are a number of literatures about the spread of financial crisis. Since the stock market crash in October 1992 and the Asian financial crisis in July 1997, a lot of researches have been devoted to investigating the covariance of stock returns between different markets. Also, although there was no sign of co-integration between the 11 Asian stock markets and the US stock market, (Sheng \& Tu, 2000) have found that, prior to the Asian financial crisis in 1997, they did exist during the financial crisis showing a contagion effect. Since 2007, a serious crisis has begun to emerge in the U.S. real estate market. In addition to affecting the U.S. stock market and because of the close connection between international financial markets, there has been a significant common trend effect in passing or spreading between international stock markets, and will soon spread to global financial activities and macroeconomic conditions. The US subprime mortgage has become the beginning of the "global financial crisis". And, at the same time, it has also disrupted the long-term equilibrium relationship. Financial or economic crisis can have serious effects on investors. Thus, this topic has prompted great interest from academic researchers. For example, studies, including Billio and Caporin (2010), Chudik and Fratzscher (2011), Schwert (2011), and Syllignakis and Kouretas (2011) have discussed the impact of the financial crisis on the stock market. All these studies show that the volatility of financial markets increased significantly during the crisis. This further suggests that volatility and correlation of financial markets will move together over time. This kind of co-movement reduces the diversified returns, especially in the stock market, and is becoming obvious.

After the financial liberalization policy implemented in the early 1980s, the background of financial globalization promoted by financial liberalization has increased the number of debts that provide loaning for speculative investment, which is considered to be the cause of the financial crisis. Open countries are becoming increasingly financially fragile. But, some literature points out that most of the developed regions of Europe seem to be unaffected by the crisis. This 
means that markets that have huge risks through trade or financial links are not necessarily the hardest hit by the crisis, mainly due to their basic national strength and corporate body constitution. These different research results do not have a consistent conclusion. Further research is beneficial for investors to diversify their assets and reduce the cost of future financial crisis. The United States is the world's largest economy and the largest consumer and importer. Due to changes, including globalization and liberalization of the trading environment, rapid development of the capital market, more free flow of funds, the electronic trading mechanism of the securities market, and the Internet connection, the transmission of information has accelerated and the links between the securities markets of various countries have continued to deepen. The U.S. maintains a close relationship with the major industrial countries in the liquidity of the financial, securities, and credit markets. Empirical findings have shown that the US stock market has a spreading effect on the stock markets of various countries during financial shocks (Forbes \& Rigobon, 2002; Azad et al., 2015; Jin \& An, 2016).

The literature mainly focuses on the existence of contagions effects between stock markets in different countries. In recent empirical literature, a number of different methods have been used to demonstrate the contagions effects of financial shocks and to compare the transfer effects of the US stock market to the stock markets of various countries before, during, and after the subprime crisis. The high degree of contagion greatly reduces the effects of investors' diversification of risk by adopting international securities portfolios, especially the effects of the contagions effects, which is more than enough to change the weight of the international stock market portfolio and make major adjustments. Predictable spreading means that profitable trading strategies, such as hedging, speculation, and arbitrage, can be developed while rejecting the efficient market hypothesis. The negative impact of the financial crisis has changed the long-term equilibrium relationship between countries. This shows a greater impact than during the "quiet period" and also increase the co-movement between financial markets. This co-movement reduces the benefits of diversification. Therefore, we also use the US financial crisis as a starting point to study how the US stock market affects the stock markets of major developed countries.

Previous literature has mainly focused on whether there is a contagions effect between stock markets in different countries. But, research on the extent of spread or dependence among countries in different periods is still scarce. Threshold autoregressive models are often used by researchers and academic institutions to consider "non-linear" or "asymmetric" characteristics. However, the model uses zero or a single random value as the threshold to convey only limited information. The goal of this research is to propose a model construction process to construct a multi-threshold TAR model to demonstrate the existence of the contagion effects of the United States against other countries and the total effects of the TAR threshold effects after considering the threshold. Furthermore, 
this research aims to find out the best asymmetry threshold for individual periods and check whether the coefficients and thresholds are different during the non-crisis period and the crisis period. The temporal correlation of global stock markets from a market-dependent perspective is studied. Based on the comparison model results, a probability ratio test is proposed, in which, the estimation of the multi-threshold TAR model is proven better than the single random TAR model and confirms that the research model is more explanatory.

The study chose the five largest industrialized countries founded in 1973 (referred to as "G5") including the United States, Japan, Germany, France, and the United Kingdom and China, which has surpassed Japan in 2010 as the world's second largest economy. They are now the world's top six economies and together account for more than $57 \%$ of the world market value. The study is used to measure the impact of the spread of the US stock market to the stock markets of the other five major industrial countries including U.K., France, Germany, Japan, and China during the financial crisis and non-crisis periods.

This paper is structured as follows: Reviews the theoretical and empirical literature in Section II; the main hypotheses and methodology in Section III, the data description and empirical results in Section IV, and the conclusions in Section $\mathrm{V}$.

\section{Review of Literature}

\subsection{Contagion Theories}

The term "contagion" was widely used after the Asian financial crisis of 1997. The financial literature distinguishes two kinds of contagions, psychological contagion and mechanical contagion. Psychological contagion focuses on the investor's behavior. And, mechanical contagion results from real and financial interdependencies between countries (Calvo et al., 1996; Kaminsky \& Reinhart, 1998). Dornbusch et al. (2000) made a preliminary definition of contagion, in which the impact of cross-market links increases significantly when a country or single market changes, as measured by the degree of the across markets co-movement on asset prices or capital flows in different times. Kaminsky et al. (2003) have another definition of contagion effect. After a major crisis event occurs in one market, it has an immediate and strong impact on another market. This is also referred to as the market trend, the price or return of assets, and the volatility of price or return after the market is impacted or during a crisis event from one market to another market. This phenomenon is called "contagion". Since the publication of Forbes and Rigobon (2002), the literatures on financial spread have increased. Contagion is defined "a significant increase in cross-market linkages after a shock to one country (or group of countries)", otherwise, a continued market correlation at high levels is considered to be "no contagion, only interdependence". According to the theory of crisis contagion, if there has been a common trend or co-movement between different countries or markets, a major impact in one of the markets will significantly affect the other. The definition 
of "contagion" became a phenomenon and is now widely used to describe the impact of financial interference from one country to another.

The World Bank has given three definitions of "contagion", which are very restrictive, restrictive and broad, depending on the degree of lenient. The broad definition of contagion refers to the transnational spread of shocks, or the general spillover effect. The restrictive definition of contagion refers to the transmission of shocks to other countries or the cross-border connections beyond any basic link among the countries and beyond the common shocks. The very restrictive definition of contagion refers to the impact of contagion that occurs when cross-country correlations increases in "crisis times" relative to correlations in a "tranquil times" (Nieh et al., 2011). The main economic base theory of this research is the theory of contagion effects and cross-country linkage channels. There are three major channels of communication between an economy or a country and other countries, financial connection, physical connection, and political connection in the economic theory of cross-border connection or influence transmission channels. Financial linkages represent cross-border, cross-economic, or cross-market links in the international financial market system (Forbes \& Rigobon, 2002). The definition of contagion in this study is based on the very strict definition given by the World Bank.

In the past, financial contagion usually uses time series models to analyze stock returns. Using time series model to analyze stock returns, the study can be divided into two methods: 1) investigation of the correlation between time series models and stock returns; 2) examining the relationship between stock returns and conditional variance. The main focus of the first method is to detect the existence of predictable patterns related to stock return sequences. Predictable patterns imply profitable trading rules while rejecting the efficient market hypothesis, such as Fama and French (1989) and Potterba and Summers (1988). And, Ding et al. (1993) indicates that there is long-term memory or mean regression of stock returns. These studies have concluded that not all time series of stock returns follow a random walk. Since 2007, US subprime mortgages have caused the "global financial crisis". The 2007-2009 global financial crisis affected global financial activities and macroeconomic conditions, which is difficult to explain with "fundamental principles" (Dimitriou, Samitas, \& Paltalidis, 2011; Dimitriou, Kenourgios, \& Simos, 2013). The U.S. subprime mortgage crisis has caused structural changes to the U.S. stock market. Due to the closer relationship between international financial markets, when the financial crisis occurs, the international stock markets have shown a significant common trend of mutual transmission or contagion. As a result, such changes in the US stock market have also spread to global financial markets and disrupted long-term equilibrium. Therefore, we study the impact of the US stock market on the stock markets of major industrial countries during this crisis. The relationship between the US stock market and the global stock market during the "financial crisis" was greater than during the "quiet period". 
Crisis in international markets include emerging and developing markets. These important historical crisis matters clearly prove that after the implementation of the financial liberalization policy, the financial vulnerability of countries that are opening up to international financial markets has become increasingly serious. In Actuality, the increasing number of debts that finance speculative investments is seen as the cause to the financial crisis. Financial or economic crisis can have serious consequences for investors. Thus, this topic has aroused great interest from academic researchers. All these studies empirically show that financial market volatility increased significantly during the crisis, which further suggests that volatility and correlation of financial markets will move together over time. Such simultaneous issues reduce diversified returns, and it is well known that this co-movement is obvious, especially in the stock market. The impact of the US subprime mortgage crisis has led to structural changes in the US stock market. At the same time, the changes in the US stock market evolved into a global financial crisis, which had a significant impact on major financial markets during this period (Longstaff, 2010; Kenourgios \& Dimitriou, 2015; Flavin \& Sheenan, 2015). Therefore, we also use the US financial crisis as a starting point to study how the US stock market affects the stock markets of major developed countries around the crisis. The United States is the world's largest economy and the largest consumer and importer. The impact and scope of the contagions effects should be greater than other countries. Due to the globalized and liberalized trading environment, the United States continues to maintain close relations with the liquidity of major industrial countries in the financial, securities and credit markets. The biggest difference from the past is the high development of derivative financial products. Empirical findings have found that the contagions effects of US stock markets on countries does exist (Forbes \& Rigobon, 2002; Azad et al., 2015; Jin \& An, 2016).

Facing the international turbulence caused by the crisis, this paper uses econometric modeling methods to verify the existence of the contagion and explain the effects of the contagion in this crisis. It will then be used as an impact across the US market and on the time-varying correlation of the international stock market.

\subsection{Empirical Research of Contagions Effects}

The literature focuses on the contagion effects between stock markets in different countries. In the empirical literature, a number of different methods have been used to measure how shocks spread internationally, such as: Heteroscedasticity-adjusted correlation coefficient test (Forbes \& Rigobon, 2002); ARCH and GARCH (Kao, Zhao, Ku, \& Nieh, 2019), cointegration techniques (Nieh et al., 2011; Nieh et al., 2012), probit model, TAR (Jawadi, Louhichi, \& Ameur, 2013) and TAR-GARCH (Chiang \& Doong, 2001). The traditional symmetric co-integration tests of Engle and Granger (1987) and the Momentum Threshold Autoregressive (M-TAR) model of Enders and Siklos (2001) are used to investi- 
gate the transmission effects in the literature. Relevant evidence has obtained that the US stock market has a contagions effects.

The traditional symmetric co-integration tests also rarely consider the issue of "non-linear" or "asymmetric" characteristics. Chiang and Doong (2001) point out that there is an asymmetrical co-integration relationship between the stock markets is. Chang (2010) further used asymmetric co-integration tests in their empirical research. In order to study how asymmetric phenomena affect the transmission effects, we used asymmetric TAR to compare the spread of the stock market in the United States and major industrial countries before and after the crisis.

\section{Hypotheses and Methodology}

Researchers and academic institutions often use the TAR model. From the traditional symmetric co-integration test of Engle and Granger (1987) and Johansen (1988), and after considering that co-integration is not necessarily a symmetrical relationship, the TAR model evolved into the asymmetric threshold co-integration model of Enders and Siklos (2001). The model uses zero or a single random value as the threshold, so that only limited information is conveyed in previous studies. In this study, a multi-threshold TAR model could be used to find the threshold of the best explanatory power in different periods. On the other hand, literatures including Mollah, Quoreshi and Zafirov (2016), Imen and Rim (2012), evidence was found that the cross-border contagion effects increased significantly during the US subprime crisis.

This paper examines contagion phenomenon during the crisis period. It empirically attests for contagion through a multiple threshold model test of 5 major industrial stock markets during the 02/Jan/1998 to 20/Sep/2019 period. Applying the asymmetric multiple threshold model to the sample of cross-border market indices returns can help to detect a significant increase in contagions effects, thus affecting the returns of the following markets: U.K., France, Germany, Japan and China with the U.S. market during the crisis.

\subsection{Linear and Nonlinear Unit Root Tests}

Many financial and economic time series show trending behavior or nonstationarity in the mean. Among various testing strategies, this paper tested both linear and nonlinear stationary series. Firstly, in linear test, we apply enhanced Dickey Fuller (ADF) test, Phillips Perron (PP) test, Kwiatkowski Phillips Schmidt Shin (KPSS) test. In addition, nonlinear tests were performed using the Kapetanios-Shin-Snell (KSS) test. The ADF test's regression includes lags of the first differences of $Y_{t}$ and its three models are expressed in the following forms:

$$
\begin{gathered}
\Delta Y_{t}=\phi Y_{t-1}+\sum_{i=1}^{k} \beta_{i} \Delta Y_{t-i}+\varepsilon_{t} \\
\Delta Y_{t}=\alpha+\phi Y_{t-1}+\sum_{i=1}^{k} \beta_{i} \Delta Y_{t-i}+\varepsilon_{t}
\end{gathered}
$$




$$
\Delta Y_{t}=\alpha+\phi Y_{t-1}+\lambda t+\sum_{i=1}^{k} \beta_{i} \Delta Y_{t-i}+\varepsilon_{t}
$$

where $t$ is the time index, $\alpha$ is an intercept constant called a drift, $\lambda$ is the coefficient on a time trend, $\phi$ is the coefficient presenting the process root, i.e., the focus of testing, $k$ is the lag order of the first-differences autoregressive process, and $\varepsilon_{t}$ is an independent identically distributed residual term.

Equation (1) is a pure random walk with the lag terms. Equation (2) possesses a drift. Equation (3) includes a drift and a time trend. The null hypothesis for the ADF test is: $H_{0}: \phi=0$, with the alternative $H_{1}:-2<\phi<0$. The ADF t-test statistic is $\bar{\phi} / s e(\widehat{\phi})$.

The PP test differs from the ADF test mainly in how it deals with serial correlation and heteroscedasticity in the error term. The PP test does not require the specification of the form of the serial correlation of $\Delta Y_{t}$ under the null, or require that the errors $\varepsilon_{t}$ be conditionally homoscedastic. The ADF and PP unit root tests are for the null hypothesis that a time series $Y_{t}$ is integrated of order one, $I(1)$. On the other hand, the KPSS unit root test is for the null that $Y_{t}$ is integrated of order zero, $I(0)$. Confirmatory analysis involves the ADF, PP, and KPSS tests obtaining consistent estimates for the unit root. In addition, the KSS test is applied since the above linear unit root tests may suffer from important power distortions in the presence of nonlinearities in the data generating process.

\subsection{Traditional Contagions Model}

The previous literature has found that U.S. financial markets are highly correlated with other stock markets, especially in times of crisis. Therefore, we build an Autoregressive model (model 1) that includes returns on the U.S. stock index and separates crisis and non-crisis periods. To examine the degree to which an industrial country stock index is affected by their own markets or U.S. stock index and contagions effects. Model 1 is as follows:

$$
Y_{t}=\beta_{0}+\beta_{1} D_{1}+\beta_{2} D_{2}+\beta_{3} Y_{t-1}+\beta_{4} X_{t-1}+\beta_{5} D_{1} X_{t-1}+\beta_{6} D_{2} X_{t-1}+\varepsilon_{t}
$$

where the $Y_{t}$ is the industrial stock index return at time $t, X_{t-1}$ is U.S. stock index return at time $t-1, D_{1}$ is the dummy of the pre-crisis period and $D_{2}$ is the dummy of the crisis period.

\subsection{Conventional TAR Model}

Testing for the long-run relationship between the U.S. return of current and previous trading days, this study utilized the threshold co-integration techniques proposed by Enders and Granger (1998) and Enders and Siklos (2001), given as follows:

$$
\begin{gathered}
Y_{1 t}=\alpha+\beta Y_{2 t}+u_{t} \\
\Delta u_{t}=I_{t} \rho_{1} u_{t-1}+\left(1-I_{t}\right) \rho_{2} u_{t-1}+\sum_{i=1}^{k} \gamma_{i} \Delta u_{t-i}+\varepsilon_{t}
\end{gathered}
$$


where $Y_{1 t}$ and $Y_{2 t}$ are co-integrated variables, $\varepsilon_{t}$ is a white noise residual term, and $\rho_{1}, \rho_{2}$, and $r_{i}$ represent regression coefficients. Finally, $I_{t}$ is an indicator function such that $\tau$ is an unknown threshold to be simulated:

$$
I_{t}=\left\{\begin{array}{c}
1 \text { if } u_{t-1} \geq \tau_{1} \\
\text { otherwise, }
\end{array}\right.
$$

The TAR model (model 2) extended from us Equation (4) is as follows:

$$
\begin{aligned}
Y_{t}= & \beta_{0}+\beta_{1} D_{1}+\beta_{2} D_{2}+\beta_{3} Y_{t-1}+\beta_{4} X_{t-1}+\beta_{5} D_{1} X_{t-1}+\beta_{6} D_{2} X_{t-1} \\
& +\beta_{7} T_{A} R_{t} X_{t-1}+\beta_{8} T_{A} R_{t} D_{t-1}+\beta_{9} T A R_{t} D_{2} X_{t-1}+\varepsilon_{t}
\end{aligned}
$$

where

$$
T A R_{t}= \begin{cases}1 & \text { if } X_{t-1} \geq \tau_{1} \\ 0 & \text { otherwise }\end{cases}
$$

\subsection{A Empirical Multiple Asymmetric Thresholds Model}

In this paper, we consider TAR model with possible multiple threshold values. Without assuming fixed number of the regimes, a method for detecting threshold values of the model. The major advantage of the methodology introduced here is that it avoids given the fixed number of thresholds, thus making it flexible. Numerical experiments examples show that the approach proposed here is effective in detecting the threshold values for various TAR models. It could handle multiple thresholds in a direct manner and shows it is feasible in practice.

Setting triple thresholds searching intervals. The threshold increments of INC1, INC2 and INC3 are derived by using $\left(\max T A R_{1}-\min T A R_{1}\right) / 5$ for threshold $\tau_{1}$ and $\left(\max T A R_{2}-\min T A R_{2}\right) / 5$ for threshold $\tau_{2}$ and $\left(\max T A R_{3}-\min T A R_{3}\right) / 5$ for threshold $\tau_{3}$.

After the coefficient estimation of the multiple TAR model is completed, a diagnostic test of the model-matched residuals is required. The Ljung-Box $Q$ statistic is checked to confirm the model's suitability. The test equation adds numerous lagged autoregressive terms for a white noise process of residuals. The multiple asymmetric threshold model (model 3) extended from Equation (8) is as follows:

$$
\begin{aligned}
Y_{t}= & \beta_{0}+\beta_{1} D_{1}+\beta_{2} D_{2}+\beta_{3} Y_{t-1}+\beta_{4} X_{t-1}+\beta_{5} D_{1} X_{t-1}+\beta_{6} D_{2} X_{t-1} \\
& +\beta_{7} T A R_{3 t} X_{t-1}+\beta_{8} T A R_{1 t} D_{1} X_{t-1}+\beta_{9} T A R_{2 t} D_{2} X_{t-1}+\sum_{j=1}^{p} \gamma_{j} Y_{t-j-1}+\varepsilon_{t}
\end{aligned}
$$

where

$$
\begin{gathered}
T A R_{1 t}= \begin{cases}1 & \text { if } X_{t-1} \geq \tau_{1} \text { in pre-crisis period } \\
0 & \text { otherwise, }\end{cases} \\
T A R_{2 t}= \begin{cases}1 & \text { if } X_{t-1} \geq \tau_{2} \text { in crisis period } \\
0 & \text { otherwise, }\end{cases} \\
T A R_{3 t}= \begin{cases}1 & \text { if } X_{t-1} \geq \tau_{3} \text { in post-crisis period } \\
0 & \text { otherwise, }\end{cases}
\end{gathered}
$$




\subsection{Hypotheses}

The long-term equilibrium relationship between stock markets has changed during the financial crisis. If the equilibrium relationship changes, there will be the contagion effects. However, the traditional analysis ignores the issue of "non-linear" or "asymmetric" characteristics. The conventional Threshold AR model is frequently used by researchers and academic institutions, which solves the nonlinear relationship. However, the model conveys limited information, using zero or a single random value as a threshold. This study intends to explore multiple asymmetric threshold effects of U.S. stock market to five major industrialized countries during turbulent economic conditions. We build a newly proposed multiple TAR model (model 3) and compared with the traditional TAR model, put forward the following hypotheses:

Hypothesis 1: The multiple TAR model is superior to the traditional TAR model.

The crisis contagion theory states that unexpected shocks are transmitted to other countries through transmission mechanisms. This effect leads to co-movement of stock markets. Literature pointed out that contagion effects exist when negative impacts occurred during the crisis. Kao, Zhao, Ku, and Nieh (2019) found out the homogeneity or non-heteroscedasticity of information transmission in international stock markets increased significantly during the period of the subprime crisis. In our model, the total contagion effect is divided into contagion effect and threshold effect, and it is expected to increase significantly during the crisis, in the following three hypotheses.

Hypothesis 2: The contagions effects of U.S. index return are greater during the crisis period.

Hypothesis 3: The threshold effects of U.S. index return are greater during the crisis period.

Hypothesis 4: The combined threshold contagions effects of U.S. index return are greater during the crisis period.

\subsection{Finding Optimal Multiple Asymmetric Threshold}

We designed a three-layered do-loop procedure of a Grid searching algorithm by using RATS econometrics software programming language. The first layer controls the threshold increments. The threshold increments, INC1 and INC2, and INC3, are narrowed down to half distances on the next run. The second and third layers simulate the better potential thresholds $\left(\tau_{1}, \tau_{2}, \tau_{3}\right)$ based on the minimum Akaike information criterion (AIC) and Schwarz's Bayesian criterion (SBC), as well as the maximum log-likelihood. The best thresholds would be kept each time until the end of the simulation.

\subsection{Likelihood Ratio Test for Hyp. H1}

Likelihood Ratio Statistic is a statistic that could be used to test single or multiple hypotheses when the constrained and unconstrained models have been esti- 
mated by maximum likelihood. The statistic is twice the difference in the unconstrained and constrained log-likelihoods.

The LR test is based on the same concept as the F test in a linear model. The F test measures the increase in the sum of squared residuals when variables are dropped from the model. The LR test is based on the difference in the log-likelihood functions for the unrestricted and restricted models. Because the MLE maximizes the log-likelihood function, dropping variables generally leads to a smaller-or at least no larger-log-likelihood. (This is similar to the fact that the $\mathrm{R}$-squared never increases when variables are dropped from a regression.) The question is whether the fall in the log-likelihood is large enough to conclude that the dropped variables are important. The likelihood ratio statistic is twice the difference in the log-likelihoods:

$$
\mathrm{LR}=2\left(L_{u r}-L_{r}\right) \sim \chi_{q ; 1-\alpha}^{2}
$$

where $L_{u r}$ is the log-likelihood value for the unrestricted model and $L_{r}$ is the log-likelihood value for the restricted model. The LR test (likelihood ratio test) is performed by estimating two models and comparing the fit of one model to the fit of the other. This study intends to explore multiple asymmetric threshold effects of U.S. stock market to five major industrialized countries during turbulent economic conditions. Our Hypothesis 1, is the newly proposed multiple TAR model (model 3) is superior to the traditional TAR model (model 2).

$$
\left\{\begin{array}{l}
H_{0}: L_{\text {model } 3} \leq L_{\text {model } 2} \\
H_{1}: L_{\text {model } 3}>L_{\text {model } 2}(\text { multiple TAR modelis greater })
\end{array}\right.
$$

\subsection{Wald Test for Hyp. $\mathrm{H} 2$ thru Hyp. H4}

Wald test is a general test statistic for testing hypotheses in a variety of econometric settings; typically, the Wald statistic has an asymptotic chi-square distribution, Wooldridge (2012). The Wald statistic measures how close the unrestricted estimates come to satisfying the restrictions under the null hypothesis $H_{0}: \widehat{\beta}_{1}=\widehat{\beta}_{2}=0$.Similar arguments could be used to obtain the asymptotic distribution of the Wald statistic for testing multiple hypotheses. Let $R$ be a $q \times(k+$ 1) matrix, with $q \leq(k+1)$. Assume that the $q$ restrictions on the $(k+1) \times 1$ vector of parameters, $\boldsymbol{\beta}$, could be expressed as $H_{0}: \boldsymbol{R} \boldsymbol{\beta}=\boldsymbol{r}$, where $\boldsymbol{r}$ is a $q \times 1$ vector of known constants. Under Assumptions TS.1' to TS.5', it could be shown that, under $H_{0}$,

$$
[\sqrt{n}(\boldsymbol{R} \hat{\boldsymbol{\beta}}-\boldsymbol{r})]^{\prime}\left(\sigma^{2} \boldsymbol{R} \boldsymbol{A}^{-1} \boldsymbol{R}^{\prime}\right)^{-1}[\sqrt{n}(\boldsymbol{R} \hat{\boldsymbol{\beta}}-\boldsymbol{r})]^{a} \sim \chi_{q}^{2}
$$

Obtain a computable statistic by replacing $A$ and s2 with their consistent estimators; doing so does not change the asymptotic distribution. The result is the so-called Wald statistic, which, after cancelling the sample sizes and doing a little algebra, could be written as

$$
W=(\boldsymbol{R} \hat{\boldsymbol{\beta}}-\boldsymbol{r})^{\prime}\left(\boldsymbol{R}\left(\boldsymbol{X}^{\prime} \boldsymbol{X}\right)^{-1} \boldsymbol{R}^{\prime}\right)^{-1}(\boldsymbol{R} \hat{\boldsymbol{\beta}}-\boldsymbol{r}) / \hat{\sigma}^{2}
$$


Under $H_{0}, \quad W_{\sim}^{a} \sim \chi_{q}^{2}$, where $q$ is the number of restrictions being tested. If $\hat{\sigma}^{2}=S S R /(n-k-1)$, it could be shown that $W / q$ is exactly the $F$ statistic for testing multiple linear restrictions.

Therefore, we check the multiple asymmetric threshold effects Model (model 3) in Equation (10) as Hyp. H2 thru H4. We test during the financial crisis period the contagions effects, threshold effects and combined threshold contagions effects are greater the average non-financial crisis period.

First, the coefficient of contagions effects in three periods are: during the financial crisis is $\beta_{4}+\beta_{6}$; during the post-crisis is $\beta_{4}$; during the pre-crisis is $\beta_{4}+\beta_{5}$. The average effects of non-financial crisis period would be $\left(\left(\beta_{4}\right)+\left(\beta_{4}+\beta_{5}\right)\right) / 2$. The Hyp. H2inference as $\beta_{4}+\beta_{6}-\left(\left(\beta_{4}\right)+\left(\beta_{4}+\beta_{5}\right)\right) / 2=0$ which we could re-write as $\beta_{6}-\beta_{5} / 2=0$.

Hypothesis 2 is as follow:

$$
\left\{\begin{array}{l}
H_{0}: \beta_{6}-\frac{\beta_{5}}{2} \leq 0 \\
H_{1}: \beta_{6}-\frac{\beta_{5}}{2}>0
\end{array}\right.
$$

Second, the coefficient of threshold effects in three periods are: during the financial crisis is $\beta_{7}+\beta_{9}$; during the post-crisis is $\beta_{7}$; during the pre-crisis is $\beta_{7}+\beta_{8}$. The average effects of non-financial crisis period would be $\left(\left(\beta_{7}\right)+\left(\beta_{7}+\beta_{8}\right)\right) / 2$. The Hyp. H3 inference as $\beta_{7}+\beta_{9}-\left(\left(\beta_{7}\right)+\left(\beta_{7}+\beta_{8}\right)\right) / 2=0$ which we could re-write as $\beta_{9}-\beta_{8} / 2=0$.

Hypothesis 3 is as follow:

$$
\left\{\begin{array}{l}
H_{0}: \beta_{9}-\frac{\beta_{8}}{2} \leq 0 \\
H_{1}: \beta_{9}-\frac{\beta_{8}}{2}>0
\end{array}\right.
$$

Third, the coefficient of combined threshold contagions effects in three periods are: during the financial crisis is $\beta_{4}+\beta_{6}+\beta_{7}+\beta_{9}$; during the post-crisis is $\beta_{4}+\beta_{7}$; during the pre-crisis is $\beta_{4}+\beta_{5}+\beta_{7}+\beta_{8}$. The average effects of non-financial crisis period would be $\left(\left(\beta_{4}+\beta_{7}\right)+\left(\beta_{4}+\beta_{5}+\beta_{7}+\beta_{8}\right)\right) / 2$. The Hyp. H4 inference as $\beta_{4}+\beta_{6}+\beta_{7}+\beta_{9}-\left(\left(\beta_{4}+\beta_{7}\right)+\left(\beta_{4}+\beta_{5}+\beta_{7}+\beta_{8}\right)\right) / 2=0$ which we could re-write as $\beta_{6}+\beta_{9}-\left(\beta_{5}+\beta_{8}\right) / 2=0$.

Hypothesis 4 is as follow:

$$
\left\{\begin{array}{l}
H_{0}: \beta_{6}+\beta_{9}-\frac{\beta_{5}+\beta_{8}}{2} \leq 0 \\
H_{1}: \beta_{6}+\beta_{9}-\frac{\beta_{5}+\beta_{8}}{2}>0
\end{array}\right.
$$

\section{Data and Empirical Results}

\subsection{Data Source}

This research analyzes the daily stock indexes of six major industrial countries in 
the world, including the United States, UK, France, Germany, China and Japan international stock indices. The United States daily stock indices are represented by the S\&P 500. For the other international stock markets, we use the following daily stock indices from five industrial countries: FTSE-100 index (U.K.), CAC-40 index (France), DAX index (Germany), SSEC (China) and Nikkei 225 index (Japan). Our daily sample period is from January 2, 1998 to September 20, 2019. Because of the time difference, the trading days of each stock market are different. Therefore, we consider the data of all simultaneous trading days in the stock market before analyzing. Since there is still no consensus in practice for the period from the occurrence to the end of the global financial crisis, it is difficult to make a clear division with exact dates. On the whole, the world's industrial stock price indices reached high levels in October-November 2007, and continues to fall till the November 2008. Therefore, this article defines this period as the "global financial crisis period". Thus, the period of "the pre-global financial crisis" was defined as the period from January 2, 1998 to October 29, 2007 and the period of "the financial crisis" was defined as the period from October 29, 2007 to November 20, 2008.

The sample in this study is the daily data that cut from January 2, 1998 to September 20, 2019 and thus contains the non-global financial crisis period as well as global financial crisis period. The sample period of the original market index daily return data set in this paper is as long as 20 years. The whole 20 -year time series is divided into three periods to observe the contagion effects in different periods. The global financial crisis is about 1 year, and the global financial crisis is 10 years before and after each, as shown in Table 1. Daily data were used for the samples, and the whole sampling period started from January 2, 1998 to September 20,2019, a total of 5465 daily observations were obtained.

The sample period covers the stable period of non-financial crises and the extreme condition market of financial crisis. This section could be used to analyze the data spanning the 10 years before and after the 2008 subprime mortgage crisis. It may be used for understanding of the global stock market's response to the financial crisis and the changes in the correlation between the stock market before and after the crisis. It is an important reference for various types of information transmission.

The return of stock price indices is the main variable of our study, which was the logarithms of the stock price ratio in this study. The return on stock price index was as follows:

$$
R_{(i, t)}=\ln \left(P_{i, t} / P_{i, t-1}\right) \times 100
$$

where $P_{t}$ and $P_{(t-1)}$ was the stock price of different periods, and $R_{(i, t)}$ was the daily stock returns of market $i$ in the period $t$, respectively.

Table 2 represents the descriptive statistics for all the returns in our study in 6 stock markets, respectively. All the stock indices have positive return means. Germany, France, China, and Japan's stock returns have the largest standard deviation, indicating that it has greater volatility than other countries' stock re- 
turns. These statistics are similar to the performance of stock markets in other countries with a standard deviation greater than the mean.

Table 1. Segmented periods from January 2, 1998 to September 20, 2019.

\begin{tabular}{cccc}
\hline & \multicolumn{2}{c}{ Period } & market opening Days \\
\hline Pre-global financial crisis & January 2, 1998 & October 28, 2007 & 2470 \\
Global financial crisis & October 29, 2007 & November 20, 2008 & 270 \\
Post-global financial crisis & November 21, 2008 & September 20, 2019 & 2725 \\
Overall Observed Time & 2 January 1998 & 20 September 2019 & 5465 \\
\hline
\end{tabular}

Table 2. Descriptive statistics of the log daily index returns.

\begin{tabular}{|c|c|c|c|c|}
\hline Country & Mean & Standard Deviation & Maximum & Minimum \\
\hline \multicolumn{5}{|c|}{ Panel A: Entire Sample } \\
\hline US & 0.0206 & 1.1974 & 10.9571 & -9.4695 \\
\hline UK & 0.0035 & 1.1648 & 9.3843 & -9.2655 \\
\hline GER & 0.0157 & 1.4800 & 10.7974 & -7.8931 \\
\hline FRN & 0.0094 & 1.4183 & 10.5945 & -9.4715 \\
\hline $\mathrm{CN}$ & 0.0187 & 1.5643 & 9.4009 & -9.2560 \\
\hline JP & 0.0020 & 1.4924 & 13.2345 & -12.1110 \\
\hline \multicolumn{5}{|c|}{ Panel B: Pre-crisis Sample } \\
\hline US & 0.0185 & 1.1304 & 5.5744 & -7.0437 \\
\hline UK & 0.0038 & 1.1500 & 5.9025 & -5.5890 \\
\hline GER & 0.0174 & 1.5824 & 7.5526 & -7.8931 \\
\hline FRN & 0.0213 & 1.4092 & 7.0022 & -6.0448 \\
\hline $\mathrm{CN}$ & 0.0629 & 1.5009 & 9.4009 & -9.2560 \\
\hline JP & -0.0016 & 1.4000 & 7.2217 & -7.2339 \\
\hline \multicolumn{5}{|c|}{ Panel C: Crisis period Sample } \\
\hline US & -0.2641 & 2.3286 & 10.9571 & -9.4695 \\
\hline UK & -0.1911 & 2.1616 & 8.4699 & -9.2655 \\
\hline GER & -0.2160 & 2.0969 & 10.7974 & -7.3355 \\
\hline FRN & -0.2245 & 2.2640 & 10.5945 & -9.4715 \\
\hline $\mathrm{CN}$ & -0.3427 & 2.8206 & 9.0344 & -8.0435 \\
\hline JP & -0.2836 & 2.7603 & 13.2345 & -12.1110 \\
\hline \multicolumn{5}{|c|}{ Panel D: Post-crisis Sample } \\
\hline US & 0.0506 & 1.0832 & 6.8366 & -9.3536 \\
\hline UK & 0.0226 & 1.0277 & 9.3843 & -5.4805 \\
\hline GER & 0.0372 & 1.2973 & 9.8428 & -7.0672 \\
\hline FRN & 0.0219 & 1.3128 & 9.6169 & -8.3843 \\
\hline $\mathrm{CN}$ & 0.0150 & 1.4359 & 5.9356 & -8.8731 \\
\hline JP & 0.0337 & 1.3895 & 7.4261 & -11.1534 \\
\hline
\end{tabular}

This table reports summary statistics of log daily index returns (in percent) for 6 markets, including the U.S. (S\&P 500 index), U.K. (FTSE-100 index), France (CAC-40 index), Germany (DAX index), China (SSEC), Japan (Nikkei 225 index), from 02/Jan/1998 to 20/Sep2019. Data are from Global Financial Data. 


\subsection{Empirical Results}

\subsubsection{Results of the Structural Breaks}

The impact of the subprime mortgage crisis on U.S. stock indices has had a structural change, and it has evolved into a global financial crisis, which seems to have a huge impact on the global major industrial financial market. Therefore, we use the crisis as the entry point to investigate the impact of the U.S. stock index on the industrial stock markets around the Global financial crisis. Furthermore, the structural break test estimates the model in Equation (4). Table 3 reports a summary of statistics of the structural break test between the financial crisis period and the non-financial crisis period. The coefficient $\beta_{2}$ is significant in all the stock indices except Japan's Nikkei index. The coefficient $\beta_{5}$ is significant in Japan's Nikkei index. This indicates the structural break exists during the financial crisis periods.

\subsubsection{Linear and Nonlinear Unit Root Tests}

Since many financial variables are not stationary in the time series or are not residual stationary of regression, this may lead to spurious regression, the Augmented Dickey-Fuller (Said \& Dickey, 1984), Phillips and Perron (1988), Kwiatkowski et al. (1992), and Kapetanios et al.'s (2003) unit root tests are conducted for the returns. The results of the four unit root tests, augmented ADF, PP, KPSS, and KSS were summarized in Table 4 The ADF, PP and KSS unit root test statistic reject the unit root null at the $1 \%$ significance level, indicating that each return series is stationary.

Table 3. Estimated results of the structural break test.

\begin{tabular}{|c|c|c|c|c|c|c|c|c|c|c|c|c|c|c|}
\hline Country & $\beta_{0}$ & & $\beta_{1}$ & & $\beta_{2}$ & & $\beta_{3}$ & & $\beta_{4}$ & & $\beta_{5}$ & & $\beta_{6}$ & \\
\hline \multirow[t]{2}{*}{ UK } & 0.0124 & - & -0.0173 & - & 0.1346 & * & -0.2299 & $* * *$ & 0.3280 & $* * *$ & 0.0750 & $* * *$ & 0.1135 & $* * *$ \\
\hline & $(0.5574)$ & & $(0.5729)$ & & $(0.0577)$ & & $(<0.0001)$ & & $(<0.0001)$ & & $(0.0068)$ & & $(0.0013)$ & \\
\hline \multirow[t]{2}{*}{ GER } & 0.0269 & - & -0.0144 & - & -0.1932 & $* *$ & -0.1840 & $* * *$ & 0.3398 & $* * *$ & 0.0428 & - & -0.0194 & - \\
\hline & $(0.3323)$ & & $(0.7193)$ & & $(0.0383)$ & & $(<0.0001)$ & & $(<0.0001)$ & & $(0.2358)$ & & $(0.6763)$ & \\
\hline \multirow[t]{2}{*}{ FRN } & 0.0085 & - & 0.0091 & - & -0.1581 & * & -0.2226 & $* * *$ & 0.3700 & $* * *$ & 0.1157 & $* * *$ & 0.0989 & $* *$ \\
\hline & $(0.7429)$ & & $(0.8088)$ & & $(0.0691)$ & & $(<0.0001)$ & & $(<0.0001)$ & & $(0.0006)$ & & $(0.0229)$ & \\
\hline \multirow[t]{2}{*}{$\mathrm{CN}$} & 0.0049 & - & 0.0568 & - & -0.2951 & $* * *$ & -0.0034 & - & 0.2316 & $* * *$ & -0.2047 & $* * *$ & 0.0445 & - \\
\hline & $(0.8716)$ & & $(0.2018)$ & & $(0.0039)$ & & $(0.8034)$ & & $(<0.0001)$ & & $(<0.0001)$ & & $(0.3933)$ & \\
\hline \multirow[t]{2}{*}{ JP } & 0.0058 & - & -0.0123 & - & -0.1043 & - & -0.1005 & $* * *$ & 0.6508 & $* * *$ & -0.1733 & $* * *$ & 0.0589 & - \\
\hline & $(0.8232)$ & & $(0.7428)$ & & $(0.2314)$ & & $(<0.0001)$ & & $(<0.0001)$ & & $(<0.0001)$ & & $(0.1859)$ & \\
\hline
\end{tabular}

${ }^{*},{ }^{* *}$, and ${ }^{* * *}$ denote significance at the $10 \%, 5 \%$, and $1 \%$ levels, respectively. $D_{1}$ is the dummy of the pre-crisis period and $D_{2}$ is the dummy of the crisis period. The numbers in parentheses are $P$-value. The table reports the estimates of the following model:

$$
Y_{t}=\beta_{0}+\beta_{1} D_{1}+\beta_{2} D_{2}+\beta_{3} Y_{t-1}+\beta_{4} X_{t-1}+\beta_{5} D_{1} X_{t-1}+\beta_{6} D_{2} X_{t-1}+\varepsilon_{t}
$$


Table 4. Unit root test results of market returns.

\begin{tabular}{|c|c|c|c|c|c|}
\hline \multirow[b]{2}{*}{ Country } & \multirow[b]{2}{*}{ Lags } & \multicolumn{3}{|c|}{ Linear tests } & \multirow{2}{*}{$\begin{array}{c}\text { Nonlinear test } \\
\text { KSS } \\
\text { t-Stat }\end{array}$} \\
\hline & & $\begin{array}{l}\text { ADF } \\
\text { t-Stat }\end{array}$ & $\begin{array}{c}P P \\
\text { t-Stat }\end{array}$ & $\begin{array}{l}\text { KPSS } \\
\text { t-Stat }\end{array}$ & \\
\hline \multirow[t]{3}{*}{ US } & 5 & $-32.4191^{\star * *}$ & $-79.4678^{* * *}$ & 0.1229 & $-8.8876^{\star * \star}$ \\
\hline & 10 & $-23.7550^{* * *}$ & $-79.8371^{* * *}$ & 0.1334 & $-7.5204^{\star * \star}$ \\
\hline & 20 & $-16.9259^{* * *}$ & $-80.0088^{* * *}$ & 0.1381 & $-5.8589^{* * *}$ \\
\hline \multirow[t]{3}{*}{ UK } & 5 & $-33.3257^{* * *}$ & $-75.4360^{* * *}$ & 0.0519 & $-6.8314^{* * *}$ \\
\hline & 10 & $-23.5909^{* * *}$ & $-75.7589^{* * \star}$ & 0.0562 & $-4.4711^{\star * \star}$ \\
\hline & 20 & $-17.3729^{* * *}$ & $-76.2349^{* * *}$ & 0.0612 & $-2.9858^{* * *}$ \\
\hline \multirow[t]{3}{*}{ GER } & 5 & $-31.8897^{\star * *}$ & $-74.3820^{* * *}$ & 0.0624 & $-6.3861^{* * *}$ \\
\hline & 10 & $-22.7318^{\star * \star}$ & $-74.5340^{* * *}$ & 0.0666 & $-3.4338^{* * *}$ \\
\hline & 20 & $-16.0551^{\star * *}$ & $-74.5598^{* * *}$ & 0.0672 & $-2.0239^{\star *}$ \\
\hline \multirow[t]{3}{*}{ FRN } & 5 & $-33.5438^{\star * *}$ & $-75.3145^{\star \star \star}$ & 0.0516 & $-5.4997^{* * *}$ \\
\hline & 10 & $-24.1044^{* * *}$ & $-75.7370^{* * *}$ & 0.0573 & $-2.8954^{* * *}$ \\
\hline & 20 & $-16.1439^{* * *}$ & $-75.9618^{* \star *}$ & 0.0598 & -1.1300 \\
\hline \multirow[t]{3}{*}{$\mathrm{CN}$} & 5 & $-29.7832^{\star * *}$ & $-70.6734^{* * *}$ & 0.0650 & $-9.8030^{* * *}$ \\
\hline & 10 & $-21.0009^{* * *}$ & $-70.6684^{* * *}$ & 0.0653 & $-5.0273^{* * *}$ \\
\hline & 20 & $-14.2351^{\star * *}$ & $-70.7926^{* * *}$ & 0.0604 & $-2.4464^{* * *}$ \\
\hline \multirow[t]{3}{*}{ JP } & 5 & $-30.9740^{* * *}$ & $-74.5270^{* * *}$ & 0.1456 & $-8.5927^{* * *}$ \\
\hline & 10 & $-21.9923^{* * *}$ & $-74.6321^{* * *}$ & 0.1525 & $-6.5066^{* * *}$ \\
\hline & 20 & $-16.4256^{* * *}$ & $-74.6703^{* * *}$ & 0.1551 & $-5.1465^{* * *}$ \\
\hline
\end{tabular}

The null hypothesis of ADF and PP were non-stationary (unit root), and the null of KPSS was stationary (non-unit root). ${ }^{*}, * *$, and ${ }^{* * *}$ denote significance at the $10 \%, 5 \%$, and $1 \%$ levels, respectively. The critical values for the $10 \%, 5 \%$ and $1 \%$ significance levels of ADF, PP and KPSS were $(-2.5674,-2.8626,-3.4346)$, $(-2.5673,-2.8626,-3.4346)$ and $(0.3470,0.4630,0.7390)$.

\subsubsection{Results of Model Comparisons}

Table 5 compares the explanatory power of the three models. According to Equations (4), (8), (10), Model 1 and 2 are compared first. Model 2 is proven to be superior at $1 \%$ significance level. Test Model 2 and 3 are then tested. Model 3 without the control variable: $\sum_{j=1}^{p} \gamma_{j} Y_{t-j-1}$ is tested to avoid the explanatory power brought by the control variable. It was found to be at least significant at $5 \%$ significance level. It shows that the multi-threshold model constructed in this paper is more explanatory. This study intends to explore multiple asymmetric threshold effects of U.S. stock market to five major industrialized countries during turbulent economic conditions. Table 5 reports a summary of testing the significance of improvement from model 1 thru Model 3. Concerning the Hyp. $\mathrm{H} 1$ is comparing conventional TAR model (Model 2) and three random thresholds TAR model (Model 3). The newly proposed multiple TAR model are significant superior to the traditional TAR model in all five major countries. 
Table 5. Testing the significance of improvement from model 1thru model 3.

\begin{tabular}{ccccccc}
\hline \multirow{2}{*}{ Country } & \multicolumn{3}{c}{ Model 2 vs Model 1 } & \multicolumn{3}{c}{ Model 3 VS Model 2 } \\
\cline { 2 - 7 } & LR21 & $P$-value & LR32 & \multicolumn{2}{c}{$P$-value } \\
\hline UK & 14.44 & 0.0001 & $* * *$ & 8.28 & 0.0039 & $* * *$ \\
GER & 19.97 & $<0.0001$ & $* * *$ & 13.15 & 0.0002 & $* * *$ \\
FRN & 11.03 & 0.0008 & $* * *$ & 5.71 & 0.0168 & $* *$ \\
CN & 39.31 & $<0.0001$ & $* * *$ & 6.04 & 0.0139 & $* *$ \\
JAP & 37.04 & $<0.0001$ & $* * *$ & 9.39 & 0.0021 & $* * *$ \\
\hline
\end{tabular}

The numbers are $x^{2}$ and the $P$-value. ${ }^{*},{ }^{*}$, and ${ }^{* *}$ denote significance at the $10 \%, 5 \%$, and $1 \%$ levels, respectively.

\subsubsection{Estimated Results of Multiple TAR Model}

Concerning these hypotheses Hyp. H2 thru Hyp. H4, we employ multiple thresholds model for estimation. The rejection of the null hypothesis proves the significance of more contagion between the countries in the crisis period. And, the countries indices evolve according to the effects impact of the trend of U.S. stock index. If this is not the case, the U.S. stock index does not have a significant impact on the returns on other indices (Table 6).

The results of the Wald test were summarized in Table 7. To test whether the contagions effects in the crisis period, the Wald Chi-square test for Hyp. The statistical result of $\mathrm{H} 2$ is the France, China and Japan had higher contagion effects during the crisis. For example FRN, the value is as high as (4.3466), China (24.1613), Japan (44.9264), these values are very significant, indicating that the indices of these industrial countries varies with the U.S index. But for U.K. and Germany the values is no significant, which shows that the indices of these two countries have a lower degree of change with the U.S. index. For test hypothesis 3 and 4, the Wald Chi-square test result for both show a significant value. The three hypotheses are significant in most of five major countries except for U.K. and Germany of Hyp. H2. The results show that, during the financial crisis period, the contagions effects are greater, the threshold effects are significant, and the combined threshold contagions effects are stronger.

\subsubsection{White Noise Test for Residuals}

After completing the coefficient estimation of the TAR model, Residual Diagnosis needs to be performed on the residuals that fit the model to check the Ljung-Box Q statistics and confirm the suitability of the model. The control variables is from the Equation (10) $\sum_{j=1}^{p} \gamma_{j} Y_{t-j-1}$, wherein the number of lag self-regression periods $j$ is increased. The residual term diagnostic test is performed when $\mathrm{P}=7$ of the seven lagged DP (p).

Furthermore, the residual diagnostic of model 3 is tested and executed using the Ljung-Box test. Residual diagnosis is calculated with 5, 10 and 15 lags, respectively, and Table 8 provides the p-value of the Ljung-Box test of autocorrelation in the standardized residuals. In Model 3, the p-values are ultimately not significant, and all residual series are tested without serial correlation (white 
noise), and we can draw this conclusion. For the time series of all 5 countries, we cannot reject the null hypothesis that there is no autocorrelation at the level of $1 \%$, which clearly indicates that the multiple TAR model specifications have successfully modeled the serial correlation of conditional mean and variance.

Table 6. Estimated results of Multiple TAR models.

\begin{tabular}{|c|c|c|c|c|c|c|c|c|c|c|}
\hline Coefficients & UK & & GER & & FRN & & $\mathrm{CN}$ & & JP & \\
\hline \multirow[t]{2}{*}{$\beta_{0}$} & 0.0135 & - & 0.0221 & - & 0.0041 & - & 0.0090 & - & 0.0140 & - \\
\hline & $(0.5241)$ & & $(0.4269)$ & & $(0.8756)$ & & $(0.7688)$ & & $(0.5905)$ & \\
\hline \multirow[t]{2}{*}{$\beta_{1}$} & 0.1016 & * & 0.1016 & $* *$ & 0.1038 & $* *$ & 0.0807 & * & -0.0164 & - \\
\hline & $(0.0736)$ & & $(0.0369)$ & & $(0.0222)$ & & $(0.0932)$ & & $(0.6614)$ & \\
\hline \multirow[t]{2}{*}{$\beta_{2}$} & -0.1506 & $* *$ & -0.1875 & $* *$ & -0.1971 & $* *$ & -0.2589 & $* *$ & -0.0268 & - \\
\hline & $(0.0352)$ & & $(0.0460)$ & & $(0.0244)$ & & $(0.0129)$ & & $(0.7618)$ & \\
\hline \multirow[t]{2}{*}{$\beta_{3}$} & -0.2336 & $* * *$ & -0.1867 & $* * *$ & -0.2296 & $* * *$ & -0.0021 & - & -0.1036 & $* * *$ \\
\hline & $(<0.0001)$ & & $(<0.0001)$ & & $(<0.0001)$ & & $(0.8810)$ & & $(<0.0001)$ & \\
\hline \multicolumn{11}{|l|}{ Contagions effects } \\
\hline \multirow[t]{2}{*}{$\beta_{4}($ Post-Crisis $)$} & 0.2159 & $* * *$ & 0.1321 & $* *$ & 0.1827 & $* * *$ & 0.2591 & $* * *$ & 0.6748 & $* * *$ \\
\hline & $(0.0002)$ & & $(0.0220)$ & & $(0.0007)$ & & $(<0.0001)$ & & $(<0.0001)$ & \\
\hline \multirow[t]{2}{*}{$\beta_{5}$ (Pre-Crisis) } & 0.1832 & $* * *$ & 0.1663 & $* * *$ & 0.2144 & $* * *$ & -0.1782 & $* * *$ & -0.3205 & $* * *$ \\
\hline & $(<0.0001)$ & & $(0.0010)$ & & $(<0.0001)$ & & $(0.0010)$ & & $(0.0007)$ & \\
\hline \multirow{2}{*}{$\beta_{6}($ Crisis $)$} & 0.2850 & $* * *$ & 0.3768 & $* * *$ & 0.3141 & $* * *$ & -0.0735 & - & 0.3421 & $* * *$ \\
\hline & $(0.0004)$ & & $(0.0001)$ & & $(0.0003)$ & & $(0.4028)$ & & $(<0.0001)$ & \\
\hline \multicolumn{11}{|c|}{ TAR Threshold effects } \\
\hline \multirow[t]{2}{*}{$\beta_{7}($ Post-Crisis $)$} & 0.1215 & $* *$ & 0.2412 & $* * *$ & 0.2178 & $* * *$ & -0.5424 & $* * *$ & -0.1781 & $* * *$ \\
\hline & $(0.0437)$ & & $(<0.0001)$ & & $(0.0001)$ & & $(<0.0001)$ & & $(0.0001)$ & \\
\hline \multirow[t]{2}{*}{$\beta_{8}($ Pre-Crisis $)$} & -0.2239 & $* * *$ & -0.2882 & $* * *$ & -0.2276 & $* * *$ & -0.0971 & - & 0.1571 & * \\
\hline & $(<0.0001)$ & & $(0.0001)$ & & $(0.0006)$ & & $(0.1420)$ & & $(0.0971)$ & \\
\hline \multirow[t]{2}{*}{$\beta_{9(}$ Crisis $)$} & -0.2210 & $* *$ & -0.4931 & $* * *$ & -0.2501 & $* * *$ & 0.2884 & $* * *$ & -0.3728 & $* * *$ \\
\hline & $(0.0138)$ & & $(<0.0001)$ & & $(0.0091)$ & & $(0.0045)$ & & $(<0.0001)$ & \\
\hline$\tau_{1}($ Pre-Crisis $)$ & -0.4398 & & -0.3765 & & -0.3765 & & -0.9154 & & -3.6099 & \\
\hline$\tau_{2}($ Crisis $)$ & -4.8531 & & -4.8531 & & -4.8531 & & -3.9807 & & -4.8531 & \\
\hline$\tau_{3}($ Post-Crisis $)$ & -4.8531 & & -3.9807 & & -3.9807 & & 5.6155 & & 3.0055 & \\
\hline AIC & 16144.22 & & 19086.93 & & 18459.24 & & 18797.91 & & 17385.33 & \\
\hline SBC & 16120.80 & & 19063.52 & & 18435.83 & & 18774.44 & & 17361.87 & \\
\hline LOGL & -8056.11 & & -9527.46 & & -9213.62 & & -9382.95 & & -8676.66 & \\
\hline $\mathrm{N}$ & 5362 & & 5369 & & 5396 & & 5089 & & 5151 & \\
\hline
\end{tabular}

The control variables of seven lagged $\mathrm{DP}(\mathrm{p})$ are omitted. The numbers in parentheses are $P$-value. ${ }^{*},{ }^{* *}$, and ${ }^{* * *}$ denote significance at the $10 \%, 5 \%$, and $1 \%$ levels, respectively. The table reports the estimates of the following model:

$$
\begin{aligned}
Y_{t}= & \beta_{0}+\beta_{1} D_{1}+\beta_{2} D_{2}+\beta_{3} Y_{t-1}+\beta_{4} X_{t-1}+\beta_{5} D_{1} X_{t-1}+\beta_{6} D_{2} X_{t-1} \\
& +\beta_{7} T A R_{3 t} X_{t-1}+\beta_{8} T A R_{1 t} D_{1} X_{t-1}+\beta_{9} T A R_{2 t} D_{2} X_{t-1}+\sum_{j=1}^{p} \gamma_{j} Y_{t-j-1}+\varepsilon_{t}
\end{aligned}
$$


Table 7. Result of the Wald test.

\begin{tabular}{cccccc}
\hline Hypothesis & UK & GER & FRN & CN & JP \\
\hline$H_{2}: \beta_{6}-\frac{\beta_{5}}{2}>0$ & 2.1558 & 2.5356 & $4.3466^{* *}$ & $24.1613^{* * *}$ & $44.9264^{* * *}$ \\
& $(0.1420)$ & $(0.1113)$ & $(0.0371)$ & $(<0.0001)$ & $(<0.0001)$ \\
$H_{3}: \beta_{9}-\frac{\beta_{8}}{2}>0$ & $20.4242^{* * *}$ & $26.0902^{* * *}$ & $20.3863^{* * *}$ & $4.9468^{* *}$ & $6.2589^{* *}$ \\
& $(<0.0001)$ & $(<0.0001)$ & $(<0.0001)$ & $(0.0261)$ & $(0.0123)$ \\
$H_{4}: \beta_{6}+\beta_{9}-\frac{\beta_{5}+\beta_{8}}{2}>0$ & $21.7511^{* * *}$ & $26.7803^{* * *}$ & $14.5372^{\star * *}$ & $3.8445^{* *}$ & $76.0363^{* * *}$ \\
\hline
\end{tabular}

The numbers are $x^{2}$ and the $P$-value are in parentheses. ${ }^{*},{ }^{* *}$, and ${ }^{* * *}$ indicate of $10 \%, 5 \%$, and $1 \%$ significance, respectively.

Table 8. The white noise test for residuals of model 3.

\begin{tabular}{cccccc}
\hline Country & UK & GER & FRN & CN & JP \\
\hline $\operatorname{Lag}(\mathrm{p})$ & $p$-value & $p$-value & $p$-value & $p$-value & $p$-value \\
\hline 5 & 0.6060 & 0.9623 & 0.8564 & 0.9983 & 0.5730 \\
10 & 0.6638 & 0.9725 & 0.9546 & 0.9998 & 0.6698 \\
15 & 0.2360 & 0.9332 & 0.4099 & 0.9221 & 0.8612 \\
\hline
\end{tabular}

${ }^{*},{ }^{* *}$, and ${ }^{* * *}$ denote significance at the $10 \%, 5 \%$, and $1 \%$ levels, respectively.

\section{Conclusion}

Academic institutions and researchers frequently use the traditional threshold AR model. However, the model threshold is only represented by zero or a single random value, which limits the information conveyed. This study intends to explore multiple asymmetric threshold effects of U.S. stock market to five major industrialized countries during turbulent economic conditions. Daily stock index returns, ranging from 1998 to 2019, are collected. Further, we employ multiple thresholds model for estimation. Concerning these four hypotheses, first, the newly proposed multiple TAR model is significant superior to the traditional TAR model. Second, the contagions effects are significant in most of five major countries except for U.K. and Germany. During the financial crisis period, the contagions effects are greater. The US stock market is highly influential and significant to the stock markets of various countries during the all period regime. The coefficients are highly significant, showing that the US is greater impacted during the financial crisis period. Of which, the contagions effects during the crisis are not significant for China. This is consistent to the result of Kao et al. (2019), which shows that the relationship between China and the United States has the influence of interdependence in the non-crisis period. Third, the threshold effects are significant in five major countries. During the financial crisis period, the threshold effects are greater. The coefficient is negative and highly significant (except China is positive) during the financial crisis period (i.e., high market volatility). Forth, the combined threshold contagions effects are significant in five major countries. During the financial crisis period, the combined threshold contagions effects are stronger. 
The empirical results may more accurately predict hedging and arbitrage trading decisions to increase expected returns, especially during periods of severe market crises. Generally, market traders can be divided into three types: risk averters, speculators or arbitrageurs. In conclusion, by using multiple TAR models to strengthen risk management, traders can make better investment and hedging decisions. Based on the inferences in this literature, the study demonstrates the spreading effects based on the economic shocks brought about during the financial crisis, and can theoretically be expanded based on the degree of impact and the scope of the impact. Future studies could use stock price volatility as the criterion for evaluating economic shocks. The degree of influence and scope of this factor could be closer to the actual operation strategy. The study can be extended to the regional economic crisis to understand the changes in thresholds and contagions effects.

\section{Conflicts of Interest}

The authors declare no conflicts of interest regarding the publication of this paper.

\section{References}

Azad, A. S. M. S., Battenb, J. A., Fang, A., \& Wickramanayake, J. (2015). International Swap Market Contagion and Volatility. Economic Modelling, 47, 355-371. https://doi.org/10.1016/j.econmod.2015.02.001

Billio, M., \& Caporin, M. (2010). Market Linkages, Variance Spillovers, and Correlation Stability: Empirical Evidence of Financial Contagion. Computational Statistics \& Data Analysis, 54, 2443-2458. https://doi.org/10.1016/j.csda.2009.03.018

Calvo, G. A., Leiderman, L., \& Reinhart, C. M. (1996). Inflows of Capital to Developing Countries in the 1990s. Journal of Economic Perspectives, 10, 123-139. https://doi.org/10.1257/jep.10.2.123

Chang, C. (2010). A Multivariate Causality Test of Carbon Dioxide Emissions, Energy Consumption and Economic Growth in China. Applied Energy, 87, 3533-3537. https://doi.org/10.1016/j.apenergy.2010.05.004

Chiang, T. C., \& Doong, S. C. (2001). Empirical Analysis of Stock Returns and Volatility: Evidence from Seven Asian Stock Markets Based on TAR-GARCH Model. Review of Quantitative Finance and Accounting, 17, 301-318. https://doi.org/10.1023/A:1012296727217

Chudik, A., \& Fratzscher, M. (2011). Identifying the Global Transmission of the 2007-2009 Financial Crisis in a GVAR Model. European Economic Review, 55, 325-339. https://doi.org/10.1016/j.euroecorev.2010.12.003

Dimitriou, D., Kenourgios, D., \& Simos, T. (2013). Global Financial Crisis and Emerging Stock Market Contagion: A Multivariate FIAPARCH-DCC Approach. International Review of Financial Analysis, 30, 46-56. https://doi.org/10.1016/j.irfa.2013.05.008

Dimitriou, D., Samitas, A., \& Paltalidis, N. (2011). Financial Crises and Stock Market Contagion in a Multivariate Time-Varying Asymmetric Framework. Journal of International Financial Markets, Institutions and Money, 21, 92-106.

https://doi.org/10.1016/j.intfin.2010.08.005 
Ding, Z., Granger, C. W. J., \& Engle, R. F. (1993). A Long Memory Property of Stock Market Returns and a New Model. Journal of Empirical Finance, 1, 83-106. https://doi.org/10.1016/0927-5398(93)90006-D

Dornbusch, R., Park, Y. C., \& Claessens, S. (2000). Contagion: How It Spreads and How It Can Be Stopped? World Bank.

Enders, W., \& Granger, C. W. J. (1998). Unit-Root Tests and Asymmetric Adjustment with an Example Using the Term Structure of Interest Rates. Journal of Business \& Economic Statistics, 16, 304-311. https://doi.org/10.1080/07350015.1998.10524769

Enders, W., \& Siklos, P. L. (2001). Cointegration and Threshold Adjustment. Journal of Business \& Economic Statistics, 19, 166-176. https://doi.org/10.1198/073500101316970395

Engle, R. F., \& Granger, C. W. J. (1987). Co-Integration and Error Correction: Representation, Estimation, and Testing. Econometrica, 55, 251-276. https://doi.org/10.2307/1913236

Fama, E. F., \& French, K. R. (1989). Business Conditions and Expected Returns on Stocks and Bonds. Journal of Financial Economics, 25, 23-49. https://doi.org/10.1016/0304-405X(89)90095-0

Flavin, T. J., \& Sheenan, L. (2015). The Role of U.S. Subprime Mortgage-Backed Assets in Propagating the Crisis: Contagion or Interdependence? The North American Journal of Economics and Finance, 34, 167-186. https://doi.org/10.1016/j.najef.2015.09.001

Forbes, K., \& Rigobon, R. (2002). No Contagion, Only Interdependence: Measuring Stock Market Comovements. Journal of Finance, 57, 2223-2261. https://doi.org/10.1111/0022-1082.00494

Imen, G. M., \& Rim, A. (2012). A Dynamic Analysis of Financial Contagion: The Case of the Subprime Crisis. Journal of Business Studies Quarterly, 4, 11-27.

Jawadi, F., Louhichi, W., \& Ameur, H. B. (2013). Do the US Trends Drive the UK-French Market Linkages?: Empirical Evidence from a Threshold Intraday Analysis. Applied Economics Letters, 20, 499-503. https://doi.org/10.1080/13504851.2012.714064

Jin, X., \& An, X. (2016). Global Financial Crisis and Emerging Stock Market Contagion: A Volatility Impulse Response Function Approach. Research in International Business and Finance, 36, 179-195. https://doi.org/10.1016/j.ribaf.2015.09.019

Johansen, S. (1988). Statistical Analysis of Cointegration Vectors. Journal of Economic Dynamics and Control, 12, 231-254. https://doi.org/10.1016/0165-1889(88)90041-3

Kaminsky, G. L., \& Reinhart, C. M. (1998). Financial Crises in Asia and Latin America: Then and Now. The American Economic Review, 88, 444-448.

Kaminsky, G. L., Reinhart, C. M., \& Vegh, C. A. (2003). The Unholy Trinity of Financial Contagion. Journal of Economic Perspectives, 17, 51-74. https://doi.org/10.1257/089533003772034899

Kao, Y. S., Zhao, K., Ku, Y. C., \& Nieh, C. C. (2019). The Asymmetric Contagion Effect from the U.S. Stock Market around the Subprime Crisis between 2007 and 2010. Economic Research-Ekonomska Istraživanja, 32, 2422-2454. https://doi.org/10.1080/1331677X.2019.1645710

Kapetanios, G., Shin, Y., \& Snell, A. (2003). Testing for a Unit Root in the Nonlinear STAR Framework. Journal of Econometrics, 112, 359-379. https://doi.org/10.1016/S0304-4076(02)00202-6

Kenourgios, D., \& Dimitriou, D. (2015). Contagion of the Global Financial Crisis and the Real Economy: A Regional Analysis. Economic Modelling, 44, 283-293. 
https://doi.org/10.1016/j.econmod.2014.10.048

Kim, S. W., \& Rogers, J. H. (1995). Evidence from Korea, Japan, and the United States. Journal of Empirical Finance, 2, 117-133. https://doi.org/10.1016/0927-5398(94)00013-7

Koutmos, G., \& Booth, G. G. (1995). Asymmetric Volatility Transmission in International Stock Markets. Journal of International Money and Finance, 14, 747-762. https://doi.org/10.1016/0261-5606(95)00031-3

Kwiatkowski, D., Phillips, P., Schmidt, P., \& Shin, Y. (1992). Testing the Null Hypothesis of Stationarity against the Alternative of a Unit Root: How Sure Are We that Economic Time Series Have a Unit Root? Journal of Econometrics, 54, 159-178. https://doi.org/10.1016/0304-4076(92)90104-Y

Longstaff, F. A. (2010). The Subprime Credit Crisis and Contagion in Financial Markets. Journal of Financial Economics, 97, 436-450. https://doi.org/10.1016/j.jfineco.2010.01.002

Mollah, S., Quoreshi, A., \& Zafirov, G. (2016). Equity Market Contagion during Global Financial and Eurozone Crises: Evidence from a Dynamic Correlation Analysis. Journal of International Financial Markets, Institutions and Money, 41, 151-167. https://doi.org/10.1016/j.intfin.2015.12.010

Nieh, C. C., Kao, Y. S., \& Yang, C. H. (2011). The Asymmetric Contagion from the U. S. Stock Market around the Subprime Crisis. In M. Susai, \& S. Uchida (Eds.), Studies on Financial Markets in East Asia (pp. 19-39). Singapore: World Scientific. https://doi.org/10.1142/9789814343374_0002

Nieh, C. C., Yang, C. H., \& Kao, Y. S. (2012). Who Has More Influence on Asian Stock Markets around the Subprime Mortgage Crisis-The US or China? Applied Economics Letters, 19, 329-335. https://doi.org/10.1080/13504851.2011.577001

Phillips, P. C. B., \& Perron, P. (1988). Testing for a Unit Root in Time Series Regression. Biometrika, 75, 335-346. https://doi.org/10.1093/biomet/75.2.335

Potterba, J. M., \& Summers, L. H. (1988). Mean Reversion in Stock Prices: Evidence and Implications. Journal of Financial Economics, 22, 27-59. https://doi.org/10.1016/0304-405X(88)90021-9

Said, S. E., \& Dickey, D. A. (1984). Testing for Unit Roots in Autoregressive Moving Average Models of Unknown Order. Biometrika, 71, 599-607. https://doi.org/10.1093/biomet/71.3.599

Schwert, G. W. (2011). Stock Volatility during the Recent Financial Crisis. European Financial Management, 17, 789-805. https://doi.org/10.1111/j.1468-036X.2011.00620.x

Sheng, H. C., \& Tu, A. H. (2000). A Study of Cointegration and Variance Decomposition among National Equity Indices before and during the Period of the Asian Financial Crisis. Journal of Multinational Financial Management, 10, 345-365. https://doi.org/10.1016/S1042-444X(00)00034-7

Syllignakis, M. N., \& Kouretas, G. P. (2011). Dynamic Correlation Analysis of Financial Contagion: Evidence from the Central and Eastern European Markets. International Review of Economics \& Finance, 20, 717-732. https://doi.org/10.1016/j.iref.2011.01.006

Wooldridge, J. M. C. (2012). Introductory Econometrics: A Modern Approach (5th ed.). Boston, MA: Cengage Learning. 